\title{
Influence of Actin Cytoskeleton on Intra-articular and Interstitial Fluid Pressures in Synovial Joints
}

\author{
A. Poli, D. Scott,* K. Bertin,* G. Miserocchi,* R. M. Mason, $\uparrow$ and J. R. Levick \\ Department of Physiology, St. George's H ospital Medical School, London SW 17 ORE, U nited Kingdom; \\ *D epartment of Experimental M edicine, University of Milan-Bicocca, M ilan, Italy; and †Cell and M ol ecular \\ Biology Section, Division of Biomedical Sciences, Imperial College School of Medicine, London, SW 7 2AZ United Kingdom
}

Received May 9, 2001; published online August 30, 2001

Fibroblast microfilamentous actin (F-actin) influences interstitial fluid pressure via linkages to collagen in rat skin (Berg et al., 2001). The present aims were to determine whether the actin cytoskeleton of synovial endothelium, fibroblasts, and synoviocytes influences in vivo (i) fluid exchange between a joint cavity and synovial microcirculation and (ii) extracellular fluid pressures in joints. Rabbit knee joints were treated intra-articularly with the Factin disrupting drugs cytochalasin D and latrunculin B while joint fluid pressure $P_{j}$ was recorded. In joints injected with small volumes of control solution, $P_{j}$ fell with time $\left(-0.05 \pm 0.01 \mathrm{~cm} \mathrm{H}_{2} \mathrm{O} \mathrm{min}^{-1}\right.$, mean $\pm \mathrm{SEM}, \mathrm{n}=\mathbf{9}$, equivalent drainage rate $\left.3.9 \mu \mathrm{m} \mathrm{min}^{-1}\right)$. Cytochalasin or latrunculin reversed this in $\sim 4 \mathrm{~min}$ in vivo; $P_{\mathrm{j}}$ increased with time, e.g., $+0.12 \pm 0.04 \mathrm{~cm} \mathrm{H}_{2} \mathrm{O} \mathrm{min}^{-1}$ at $200 \mu \mathrm{M}$ cytochalasin (equivalent filtration rate into joint 6.6-12.5 $\mu \mathrm{min}^{-1}, \mathrm{n}=4$ ), with a cytochalasin $\mathrm{EC}_{50}$ of 45 $\mu \mathrm{M}$. Plasma $\gamma$-globulin clearance into the joint cavity was also increased. Post mortem, cytochal asin did not reverse $\mathrm{dP}_{\mathrm{j}} / \mathrm{dt}$ and had no more effect on $\mathbf{P}_{\mathrm{j}}$ than did control solution. Also, when synovial interstitial fluid pressures were measured by servonull micropipette post mortem (control $-0.95 \pm 0.37 \mathrm{cmH}_{2} \mathrm{O}, \mathrm{n}=18$ ) cytochalasin had no significant effect on interstitial pressure over $60 \mathrm{~min}$, even at $1 \mathrm{mM}$. It was concluded that synovial endothelial F-actin has an important role in the normal synovial microvascular resistance to fluid filtration and plasma $\gamma$-globulin permeation and is thus a potential link between pro-in- flammatory mediators and arthritic joint effusions. The results provided no support for the hypothesis that synoviocyte F-actin influences the swelling tendency of synovial matrix and hence extracellular fluid pressures, in contrast to the findings of Berg et al. (2001) in rat dermis. 02001 Academic Press

Key W ords: Cytochalasin; latrunculin; actin; endothelial permeability; synovium.

\section{INTRODUCTION}

Synovium is a thin, mesenchyme-derived sheet of tissue responsible for the generation, encapsulation, and drainage of synovial fluid in joints. A superficial network of fenestrated microvessels filters fluid slowly into the joint cavity when intra-articular pressure is low, as in extended joints. In synovitis a breakdown of the endothelial barrier leads to the development of a protein-rich effusion in the joint cavity (Wallis et al., 1987). When synovial fluid pressure is raised, e.g., by flexion, the net trans-synovial flow reverses direction and fluid is driven out of the joint cavity. The fluid passes between the discontinuous synoviocytes (specialized fibroblasts; Edwards, 1999) that line the surface and drains into a subsynovial lymphatic system. The intersynoviocyte pathway comprises a matrix of types I, III, IV, V, and VI colla- 
gen, hyaluronan, sulfated proteoglycans, and fibronectin (Levick et al., 1996), and its level of hydration is an important factor influencing its permeability.

Our interest in the role of filamentous actin (F-actin) in synovial cells arose from reports that F-actin in fibroblasts modulates the interstitial fluid pressure and hydration of rat skin (Reed et al., 1997; Berg et al., 2001). F-actin is a ubiquitous cytoskeletal microfilament that is present in endothelium (see below), fibroblasts (Ribeiro et al., 1997), and their close relatives, the synoviocytes that line a joint cavity (Ward et al., 1999). The F-actin is linked to the extracellular matrix through membrane integrins (Takenaga et al., 1990). In endothelium, the actin microfilaments also link with the intercellular junction protein complex (Dejana et al., 1995). The work of Reed's group, using servonull micropipettes to measure pressure, indicated that the fibroblast cytoskeleton exerts a tonic tension on interstitial collagen through $\alpha_{2} \beta_{1}$-integrins, thereby opposing the interstitial glycosaminoglycan swelling pressure and the innate tendency of the tissue to hydrate. Disruption of this equilibrium, using antibodies against $\alpha_{2} \beta_{1}$-integrin or the F-actin disrupting agent cytochalasin, caused interstitial fluid pressure to fall to more subatmospheric values over 30-60 min, due to expression of the unopposed gel swelling pressure. In synoviocytes the cytoskeleton is likewise linked to the extracellular matrix by $\beta_{1}$ integrins (Rinaldi et al., 1997) and to hyaluronan through CD44 (Lacy and Underhill, 1985; Henderson et al., 1993; Asari et al., 1995). One aim, therefore, was to investigate whether synoviocyte F-actin influences extracellular fluid pressures in joints.

The negative pressure responses described by Reed's group were clearly demonstrated only post mortem, when circulatory stasis prevents a secondary rise in interstitial hydration. In vivo, by contrast, cytochalasin caused increases in the hydration and the albumin content of rat dermis, indicating that F-actin also contributes to endothelial barrier function in rat skin (Berg et al., 2001). This is in keeping with studies of continuous endothelium monolayers in vitro, which show that cytochalasin disrupts phalloidin-labeled microfilaments and causes cell retraction, intercellular gap formation, and a raised permeability (Shasby et al., 1982; Alexander et al., 1988; Haselton et al., 1989; Holda and Blatter, 1997; Kevil et al., 1998). Moreover, changes in F-actin distribution and disruption of the peripheral F-actin ring are features of inflammation in venular endothelium (Baldwin and Thurston, 1995; Ehringer et al., 1999). In vivo, intravascular cytochalasin causes edema, a fall in the albumin reflection coefficient, and a rise in the microvascular filtration capacity (Shasby et al., 1982; Korthuis et al., 1991; Ermert et al., 1995). In view of the above findings, a second aim was to investigate whether F-actin influences the movement of fluid across the fenestrated capillaries of synovium and hence whether it has a potential role in the formation of joint effusions.

The above aims were addressed by experiments using two F-actin disrupting drugs. Cytochalasin D is a fungal metabolite that disrupts actin microfilaments in minutes, primarily by capping the barbed, growing end of the actin filament. Actin filaments are dynamic structures that undergo a continuous, rapid, treadmilltype turnover, in which monomeric G-actin is continuously removed from one end and added to the opposite end at a rate of $>4.5 \mu \mathrm{m} \mathrm{min}{ }^{-1}$ (Symons and Mitchison, 1991; Alberts et al., 1994). Blockage of the growing end by cytochalasin is thus quickly followed by filament disassembly. Rapid disassembly of F-actin has been confirmed both in endothelium (Holda and Blatter, 1997; Wang, 1998) and in fibroblasts (Ribeiro et al., 1997). Additional mechanisms may contribute to F-actin disruption at high drug concentrations (Cooper, 1987).

To confirm the specificity of cytochalasin D-induced effects, we also carried out experiments with latrunculin B, a Red Sea sponge toxin that inhibits F-actin polymerization by a different mechanism. Latrunculin binds to the cytosolic pool of G-actin and thus reduces its availability, which leads to disruption of the rapidly turning over F-actin microfilaments (Spector et al., 1983; Coué et al., 1987; de Oliveira and Mantovani, 1988).

\section{METHODS}

In an initial series of experiments in vivo, F-actin disrupting drug was injected into the joint cavity of 
rabbit knees under anesthesia and resulting changes in joint fluid pressure $\left(P_{\mathrm{j}}\right)$ were recorded through a cannula for $30 \mathrm{~min}$. A fall in pressure indicated net drainage of fluid from the cavity, whereas a rise indicated net filtration into the cavity. The experiment was repeated on the contralateral joint using a control solution or low dose of drug. The pressure response in the joint cavity to cytochalasin D was also studied post mortem. The reasoning behind the latter study was that any increase in the swelling tendency of synovial interstitium will cause the absorption of some intraarticular fluid post mortem and thus be revealed by a fall in articular fluid pressure. In a second series of experiments, designed to reproduce closely the servonull micropipette method of Berg et al. (2001), minute boluses of drug at various concentrations were injected directly into the exposed synovial tissue post mortem, and interstitial fluid pressure in the adjacent tissue was monitored by a servonull micropipette system for up to $60 \mathrm{~min}$.

\section{Experimental Preparation in Vivo}

New Zealand white rabbits weighing $2.5-3 \mathrm{~kg}$ were anesthetized with $30 \mathrm{mg} \mathrm{kg}^{-1}$ sodium pentobarbitone plus $500 \mathrm{mg} \mathrm{kg}^{-1}$ urethane iv and tracheostomized. Anesthesia was maintained at sufficient depth to abolish the corneal blink reflex using intravenous $15 \mathrm{mg}$ sodium pentobarbitone plus $250 \mathrm{mg}$ urethane every 30 min. Procedures conformed to local animal legislation and animals were killed by an overdose of iv sodium pentobarbitone at the end of the experiment. The intra-articular cannulation and pressure-recording systems were as described by Coleman et al. (1999).

\section{Intra-articular Injections and Rate of Change of Joint Fluid Pressure, $\mathrm{dP}_{\mathrm{j}} / \mathrm{dt}$}

A 21-gauge cannula was inserted into the joint cavity and connected to a water-calibrated differential pressure transducer to measure $P_{\mathrm{j}}$. A bolus of 150-400 $\mu l$ of test solution was injected into the joint cavity through the pressure line, raising $P_{\mathrm{j}}$ to just above atmospheric pressure, and $P_{\mathrm{j}}$ was recorded for $30 \mathrm{~min}$. Since $P_{\mathrm{j}}$ is related to the volume of fluid $V$ present in the joint cavity through a known compliance curve
(Knight and Levick, 1982, 1983), the rate of change of pressure $d P_{\mathrm{j}} / d t$ served as a measure of $d V / d t$, i.e., the net trans-synovial flow $\left(\dot{Q}_{s}\right)$. Slopes on the chart record were fitted by ruler.

\section{Interstitial Pressure Measurements by the Servonull Micropipette System Post Mortem}

The servonull feedback system (Vista Electronics Co., Ramona, CA) utilized changes in electrical resistance in a $1 \mathrm{M} \mathrm{NaCl}$-filled micropipette, caused by minute flows of interstitial fluid through the tip, to control a pump that adjusts the pressure in the micropipette until it balances that of the interstitial fluid. The method has been evaluated by Wiig et al. (1981). The system used here was as described by Miserocchi et al. (1990). Briefly, glass micropipettes of outer diameter $1 \mathrm{~mm}$ with ground, beveled tips of diameter of 2-5 $\mu \mathrm{m}$ were filled with $1 \mathrm{M} \mathrm{NaCl}$, which was colored with lissamine green for tip visualization. The system's P23XL pressure transducer (Gould Instruments, Cleveland, $\mathrm{OH}$ ) was precalibrated with a water column. The linearity of calibration of each micropipette was checked by inserting it into a sealed chamber of normal saline connected to a second water column. Zero level (atmospheric pressure) was set with the tip touching a small pool of normal saline level with the micropuncture site. Output was recorded on a thermal oscillograph (Gould Instruments).

Interstitial fluid pressures were measured in the synovial lining of joint cavities that were opened immediately after the animal was killed by an anesthetic overdose. A central flap of tissue was raised by means of a transverse incision across the insertion of the patellar tendon, extended proximally by two parallel incisions along the medial and lateral sides of the patellar ligament and patella. The resulting flap was retracted to access the joint cavity. The lateral margin of the joint capsule was then retracted to expose a sheet of lateral suprapatellar synovium. The underside of the retracted tissue was supported by a plasticine mold. The space between the tissue, the microscope objective, and the micropipette was enclosed by a continuous seal of polyvinyl chloride/ethylene film (Cling Film, Woolworths, UK) to maintain local humidity. Superfusion was not used, in order to avoid 
overhydration of the interstitium prior to the pressure measurements.

After the initial, control measurements of synovial and subsynovial interstitial pressures (see below), 1.5 $\mu l$ of test solution was injected as superficially as possible under the exposed lateral suprapatellar synovium, using a 34-gauge needle and a 10- $\mu$ l Hamilton syringe (Hamilton, Sutton, England), which was held at a shallow angle. Since the needle was thicker than the synovium, the fluid was delivered into the subsynovium rather than the synovium itself. The volume injected was too small to raise a visible surface bleb.

The micropipette was mounted in a MO-102 micromanipulator (Narishige, Tokyo, Japan). After the zero pressure reading was checked with the tip touching the tissue surface, the tip was advanced into the synovium under stereomicroscopic guidance (SMZ-2T stereomicroscope, Nikon, Tokyo, Japan). The vertical depth of the tip was calculated as $h \cdot \sin \theta$, where $\theta$ was the angle of insertion $\left(\sim 45^{\circ}\right)$ and $h$ the distance advanced obliquely, as read from the micromanipulator scale in micrometers. Since the arithmetic mean thickness of rabbit synovium in the suprapatellar pouch is $16-19 \mu \mathrm{m}$, and that of the subsynovium is $\sim 100 \mu \mathrm{m}$ (Knight and Levick, 1983; Levick and McDonald, 1989a), measurements taken at tip depths of $<10 \mu \mathrm{m}$ were classified as synovial interstitial pressures and those at 20-35 $\mu \mathrm{m}$ were classified as subsynovial interstitial pressures. The region between 10 and $20 \mu \mathrm{m}$ was ignored due to the uncertainty over tissue type near the synovium/subsynovium boundary during a blind penetration. After stable pressures were recorded for $10 \mathrm{~s}$ or so in the synovium and subsynovium, the micropipette was withdrawn and the zero rechecked. Readings were accepted if the pipette zero reading was the same before and after insertion, and if the tissue surface was not visibly distorted by entry of the micropipette. Changing the gain of the servonull system without a consequent change in recorded pressure provided a further check on the system in control experiments. Pressure measurements were repeated at 10-min intervals for an hour, moving the micropipette tip around the perimeter of the injection site so that each measurement was $10-15 \mu \mathrm{m}$ from the previous site but equidistant from the injection center.

Measurements were taken at points $1 \mathrm{~mm}$ radially from the center of the injection site. The radial distance was marked lightly on the tissue surface at four points at the outset, using another micropipette dipped in a lissamine green solution. The distance selected for measurements represented a compromise between avoiding the central region where pressure was raised by the injection yet remaining within the region reached by the drug. Following the approach of Berg et al. (1998), measurements were made just beyond the edge of the injected bolus, which would be at $0.7-\mathrm{mm}$ radius for a 1.5- $\mu \mathrm{l}$ sphere. A pilot study showed that pressure fell from $+7.5 \mathrm{~cm} \mathrm{H}_{2} \mathrm{O}$ in the center of the injection site to $-1.5 \mathrm{~cm} \mathrm{H}_{2} \mathrm{O}$ at the $1-\mathrm{mm}$ radial distance. Since a small solute such as cytochalasin, with a diffusivity similar to that of glucose, achieves $99 \%$ diffusional equilibration across $1 \mathrm{~mm}$ in $9.3 \mathrm{~min}$, even when unaided by convection, it was concluded that tissue only $\sim 0.3 \mathrm{~mm}$ from the edge of the initial bolus will be exposed to drug within minutes of its injection, albeit at subnominal concentrations.

\section{Small Solute Clearance from Joint C avity}

The intra-articular concentration of a small, rapidly diffusible solute such as cytochalasin D (508 Da) must decay with time in vivo due to diffusional clearance into the fenestrated capillaries and periarticular tissue. A preliminary calculation of clearance by the microcirculation predicted a substantial rate of decay, as follows. For flow-limited (i.e., maximal) microvascular clearance by an estimated plasma flow of $\sim 40 \mu \mathrm{l}$ $\min ^{-1}$ per knee, the solute half-life would be $\sim 17 \mathrm{~min}$ in a joint cavity containing $1 \mathrm{ml}$ fluid (corresponding pressure $\sim 6 \mathrm{~cm} \mathrm{H}_{2} \mathrm{O}$ ). To test this experimentally, the clearance of three small, colored solutes was assessed in vivo and post mortem by injecting $1 \mathrm{ml}$ of solution into the joint cavity at time zero and aspirating small aliquots at 8, 16, and $32 \mathrm{~min}$. Solute concentrations were assayed by optical absorbance in a spectrophotometer. The three solutes were acridine orange (370 $\mathrm{Da}$, lipid and water soluble, absorption peak $482 \mathrm{~nm}$ ), patent blue V (582 Da, water soluble only, absorption peak $636 \mathrm{~nm}$ ), and Evans blue (963 Da, water soluble only, absorption peak $605 \mathrm{~nm}$ ). Cytochalasin itself had no convenient absorption maximum for assay. 


\section{Plasma G lobulin Permeation into Joint Cavity}

To assess the transcapillary permeation of native plasma protein into the joint cavity, a pair of joints was infused with $100 \mu \mathrm{M}$ cytochalasin D and control solution, respectively. Fluid was aspirated at 15-min intervals and replaced by fresh solution, and the experiment continued for $>1 \mathrm{~h}$. Aspirates, along with a sample of ear vein plasma, were analyzed for native $\gamma$-globulin by polyacrylamide gel electrophoresis $(\mathrm{Nu}-$ Page Electrophoresis System, Novex Electrophoresis, Frankfurt, Germany). Gels and standards stained with Coomassie blue were read using a Fluor-S MultiImager system (Bio-Rad, Hercules, CA). Net flux of $\gamma$-globulin into the joint cavity was calculated as concentration $\times$ intra-articular volume/time.

\section{Materials}

Cytochalasin D and latrunculin B were purchased from Calbiochem (Nottingham, UK). Cytochalasin D (1 mg) was dissolved in $0.5 \mathrm{ml}$ dimethyl sulfoxide, which was then added drop by drop to phosphatebuffered saline ( $\mathrm{pH}$ 7.4) with continuous rapid stirring to prevent precipitation, until the required dilution was reached. The infused concentrations were $0,1,10$, $25,50,100$, and $200 \mu \mathrm{M}$ cytochalasin D, each of which was studied in triplicate or more. Due to its high cost, only a limited study was carried out with $1 \mathrm{mM}$ cytochalasin, the concentration studied by Berg et al. (2001). The broad-spectrum protease inhibitor $\alpha_{2}$-macroglobulin was included in one experiment with 200 $\mu \mathrm{M}$ cytochalasin $\mathrm{D}$ to test whether activation of tissue protease played any role (Unemori and Werb, 1986). Latrunculin was infused at $100 \mu \mathrm{M}$. Control solutions contained the same concentration of dimethyl sulfoxide as the contralateral test solution. The Ringer solution comprised $147 \mathrm{mM} \mathrm{Na}^{+}, 4 \mathrm{mM} \mathrm{K}^{+}, 2 \mathrm{mM} \mathrm{Ca}^{2+}$, and $156 \mathrm{mM} \mathrm{Cl}^{-}$at $\mathrm{pH} 7.2$ (Baxter Healthcare Ltd., Thetford, Norfolk, UK).

\section{Statistical Methods}

Results were compared using Student's $t$ test or analysis of variance (ANOVA) as appropriate, with $P \leq 0.05$ considered a significant difference. $\mathrm{EC}_{50}$ was

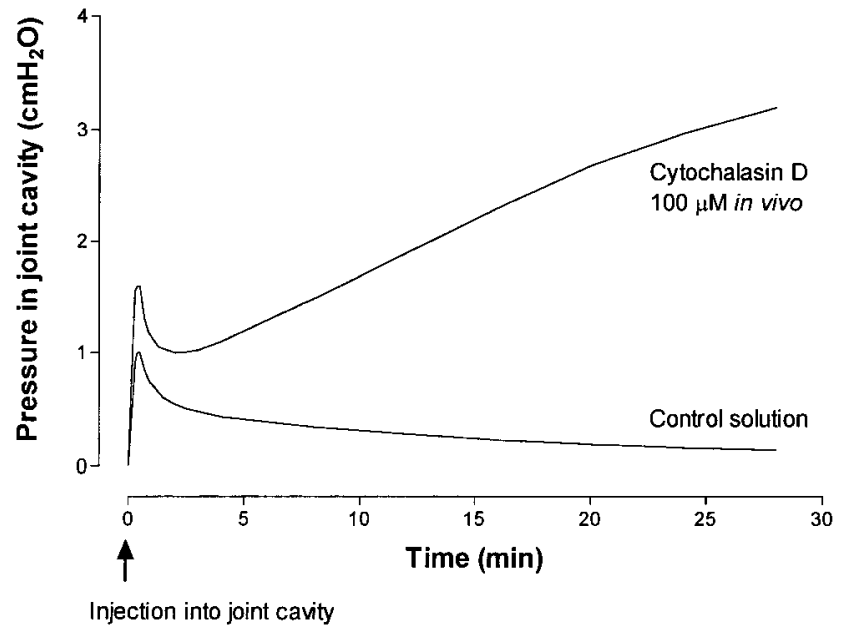

FIG. 1. Effect of intra-articular injection of $100 \mu \mathrm{M}$ cytochalasin D or vehicle (Ringer solution containing $2.5 \%$ dimethyl sulfoxide) on pressure in contralateral knees of the same animal in vivo. The initial spike was caused by the injection volume, $\sim 300 \mu \mathrm{l}$. In the control joint the pressure then decayed as the injectate drained out through the synovial lining. Cytochalasin halted the decay in $3 \mathrm{~min}$ and initiated a rise in intra-articular pressure, indicating the development of an effusion. Measurements of $d P_{\mathrm{j}} / d t$ were taken at the time of maximum rate of increase $\left(t_{\max }\right), \sim 10 \mathrm{~min}$ in this case.

estimated by fitting a 4-parameter logistic equation (top, bottom, Hill slope, $\mathrm{EC}_{50}$; GraphPad Prism, San Diego, CA) to the logarithmic dose-response curve. Means are followed by their standard errors throughout.

\section{RESULTS}

\section{Effect of Cytochalasin on Intra-articular Pressure and Microvascular Filtration in Vivo}

When control solution was injected into the joint cavity, raising pressure initially to $1-2 \mathrm{~cm} \mathrm{H}_{2} \mathrm{O}, P_{\mathrm{j}}$ decayed slowly over the next $30 \mathrm{~min}(n=9)$ (Fig. 1$)$. The decay is due to drainage of the injected fluid through the synovial interstitial pathway into the subsynovium, where the endogenous fluid pressure is subatmospheric (Scott et al., 2000b). In marked contrast, when cytochalasin D solution at $\geq 50 \mu \mathrm{M}$ was injected into the cavity, the normal decay in $P_{\mathrm{j}}$ with time ceased within a few minutes and reversed direc- 


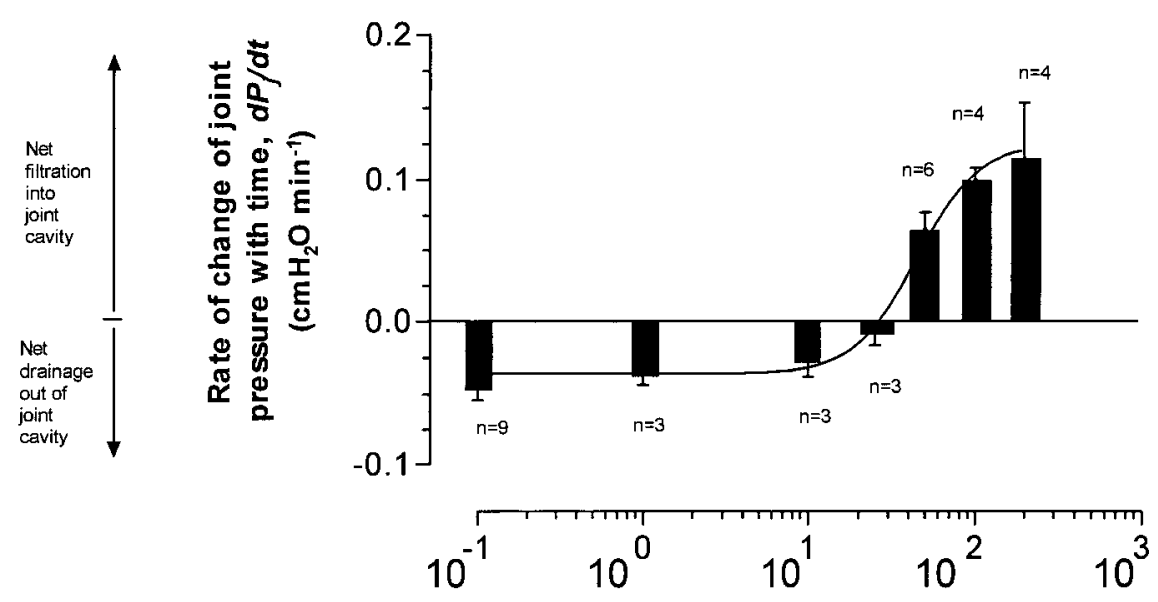

Cytochalasin D concentration $(\mu \mathrm{M})$

FIG . 2. Concentration-response relation for the effect of $1-200 \mu \mathrm{M}$ cytochalasin $\mathrm{D}$ in vivo on $d P_{\mathrm{j}} / d t$ at $t_{\max }$ (mean $\pm \mathrm{SEM}$ ). Results for vehicle alone (zero concentration) are plotted at $10^{-1} \mu \mathrm{M}$. The fitted curve, with an $\mathrm{EC}_{50}$ of $45 \mu \mathrm{M}$, is described under Statistical Methods.

tion at $4.2 \pm 0.9 \min (n=14)$ (Fig. 1$)$. Pressure then increased with time, indicating a switch to net transsynovial filtration of fluid into the joint cavity. The pressure gradually climbed higher than the initial spike of $P_{\mathrm{j}}$ caused by the injected volume. The rate of rise gradually slowed as $P_{\mathrm{j}}$ increased. Even so, in a few joints studied for $1 \mathrm{~h}$, the pressure was still rising slowly at $60 \mathrm{~min}$, despite the fact that $P_{\mathrm{j}}$ had reached 6-7 $\mathrm{cm} \mathrm{H}_{2} \mathrm{O}$.

The rate of pressure change $d P_{\mathrm{j}} / d t$ depended on the concentration of cytochalasin D $(P<0.001$, one-way ANOVA). Treatment with cytochalasin at $\geq 50 \mu \mathrm{M}$ reversed $d P_{\mathrm{j}} / d t$ to positive values in all cases $(P<$ 0.05 , Bonferroni's test, $n=14$ ), whereas none of the joints treated with 1-10 $\mu \mathrm{M}$ cytochalasin showed a reversal of the negative $d P_{\mathrm{j}} / d t(n=6)$. The time at which the rate of pressure rise following $\geq 50 \mu \mathrm{M}$ cytochalasin was steepest, $t_{\max }$, was $\sim 10 \mathrm{~min}$ after the injection. The relation between $d P_{\mathrm{j}} / d t$ at $t_{\max }$ and the logarithm of concentration was sigmoidal (Fig. 2). Cytochalasin had little effect at $1 \mu \mathrm{M}\left(d P_{\mathrm{j}} / d t=-0.033 \pm\right.$ $0.010 \mathrm{~cm} \mathrm{H}_{2} \mathrm{O} \mathrm{min}^{-1}$, pressure $0.53 \pm 0.09 \mathrm{~cm} \mathrm{H}_{2} \mathrm{O}, n=$ 3) or $10 \mu \mathrm{M}\left(d P_{\mathrm{j}} / d t=-0.028 \pm 0.010 \mathrm{~cm} \mathrm{H}_{2} \mathrm{O} \mathrm{min}{ }^{-1}\right.$, pressure $0.30 \pm 0.30 \mathrm{~cm} \mathrm{H}_{2} \mathrm{O}, n=3$ ), and the effect appeared to approach a maximum by $200 \mu \mathrm{M}\left(d P_{\mathrm{j}}\right)$ $d t=+0.115 \pm 0.039 \mathrm{~cm} \mathrm{H}_{2} \mathrm{O} \mathrm{min}{ }^{-1}$, pressure $4.9 \pm 1.0$ $\left.\mathrm{cm} \mathrm{H}_{2} \mathrm{O}, n=4\right)$. In the control joints $d P_{\mathrm{j}} / d t$ at times corresponding to $t_{\max }$ was $-0.046 \pm 0.008 \mathrm{~cm} \mathrm{H}_{2} \mathrm{O}$ $\min ^{-1}$ (pressure $0.38 \pm 0.27 \mathrm{~cm} \mathrm{H}_{2} \mathrm{O}, n=9$ ). The estimated $\mathrm{EC}_{50}$ was $44.6 \mu \mathrm{M}$, with $95 \%$ confidence intervals of $36-55 \mu \mathrm{M}$.

Net trans-synovial flow was calculated as $d P_{\mathrm{j}} / d t$ multiplied by the compliance $d V / d P_{\mathrm{j}}$ at the corresponding pressure. Compliance values were taken from Knight and Levick (1982). For the control solution the average trans-synovial drainage rate was 3.9 $\mu 1 \mathrm{~min}^{-1}$ at times corresponding to contralateral $t_{\max }$. (Drainage is allocated a positive sign for consistency with previous work.) After treatment with $200 \mu \mathrm{M}$ cytochalasin $\mathrm{D}$ the trans-synovial flows at $t_{\max }$ were in

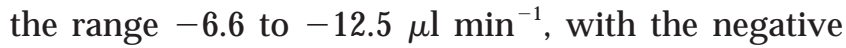
sign indicating net filtration into the cavity. Experiments post mortem showed that the microcirculation was responsible for the filtration into the cavity (see below). The effect of cytochalasin in joints was thus to initiate the rapid development of a joint effusion.

Although cytochalasin is known to act directly on endothelium (see Introduction), we also tested whether tissue protease activation might contribute to the response. The broad-spectrum protease inhibitor $\alpha_{2}$-macroglobulin was added to $10 \mathrm{ml}$ of $200 \mu \mathrm{M}$ cytochalasin D in one experiment. The quantity of $\alpha_{2}$ macroglobulin, $1 \mathrm{mg}$, was sufficient to inhibit $>10 \mu \mathrm{g}$ of trypsin activity or $10^{4}$ BAEE units per milligram of 


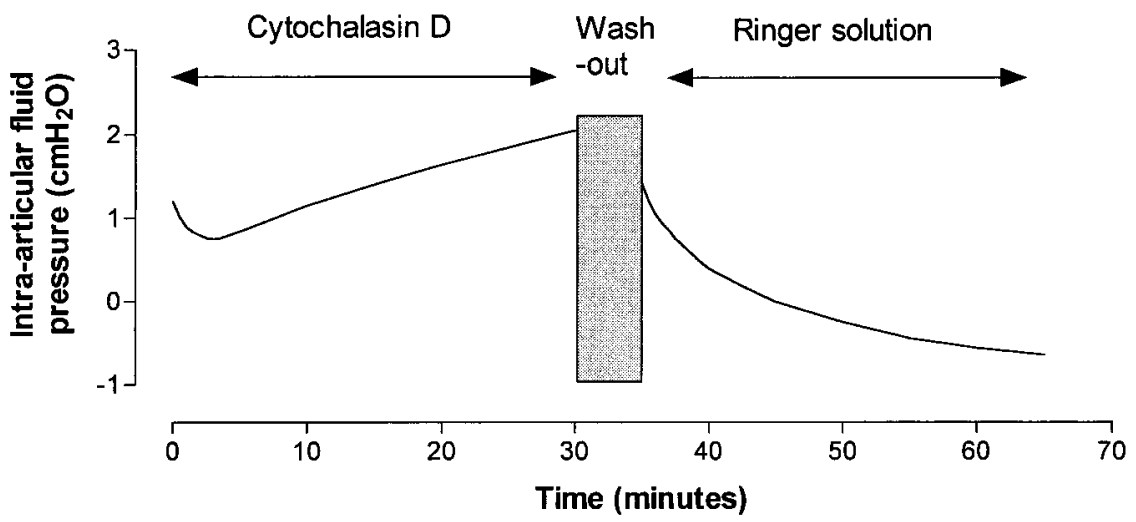

FIG. 3. Reversibility of the effect of $50 \mu \mathrm{M}$ cytochalasin $\mathrm{D}$ on intra-articular pressure in vivo. The rising pressure indicated net filtration into the joint cavity in response to cytochalasin D. The falling pressure after washout of cytochalasin D with Ringer solution indicated net drainage out of the joint cavity.

protein. It had no effect, however, on the pressurereversal response to cytochalasin D. Slope $d P_{\mathrm{j}} / d t$ reversed direction within $2 \mathrm{~min}$ and increased to +0.113 $\mathrm{cm} \mathrm{H}_{2} \mathrm{O} \mathrm{min}^{-1}$, which is equivalent to a net filtration

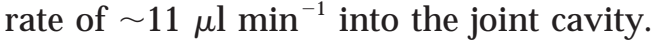

\section{Effect of Latrunculin B on Intra-articular Pressure in Vivo}

In two joints latrunculin B $(100 \mu \mathrm{M})$ was substituted for cytochalasin D in the standard protocol. Within 6 min of the latrunculin injection, $P_{\mathrm{j}}$ ceased to fall and began to rise. The rate of pressure increase, $0.033 \mathrm{~cm}$ $\mathrm{H}_{2} \mathrm{O}$ min $^{-1}$ (mean of two), was equivalent to a net filtration of $3 \mu \mathrm{l} \mathrm{min}{ }^{-1}$ into the cavity. Since lantrunculin and cytochalasin both disrupt F-actin, but by different mechanisms, the results support the view that reversal of $d P_{\mathrm{j}} / d t$ is mediated by the breakdown of actin microfilaments.

\section{Reversibility of Effect of Cytochalasin on Intra- articular Pressure and Filtration}

The reversibility of the action of cytochalasin was investigated in three joints. After the effect of a 200- $\mu$ l intra-articular injection of $50 \mu \mathrm{M}$ cytochalasin D on $d P_{\mathrm{j}} / d t$ for $30 \mathrm{~min}$ was recorded, the cavity was washed out with Ringer solution $(3 \times 200-\mu l$ washes $)$ and aspirated. The response of $d P_{\mathrm{j}} / d t$ to a 200- $\mu$ l injection of Ringer solution was then recorded for another 30 min (Fig. 3). Following the initial cytochalasin injection, $P_{\mathrm{j}}$ began to rise at $\sim 4 \mathrm{~min}$ and continued to increase until the washout at $30 \mathrm{~min}$. After the washout and injection of Ringer solution to approximately the same starting pressure, the pressure decayed slowly with time, as in an untreated joint. The cytochalasin-induced positive $d P_{\mathrm{j}} / d t$ was thus readily reversed. Rapid reversal of drug action from positive $d P_{\mathrm{j}} / d t$ (net filtration) to negative $d P_{\mathrm{j}} / d t$ (net drainage) occurred in two joints, while in the third joint there was a partial reversal; i.e., $d P_{\mathrm{j}} / d t$ remained positive but its magnitude was much reduced.

\section{Effect of Cytochalasin D on Intra-articular Fluid Pressure Post Mortem}

To demonstrate the effect of rat dermal fibroblasts on interstitial fluid pressure, Berg et al. (2001) injected cytochalasin D post mortem; this prevented microvascular filtration from masking an increasing negativity of the interstitial fluid pressure. Since synovial fluid is in direct contact with the synovial interstitium, we looked for an analogous effect by measuring the response of $P_{\mathrm{j}}$ to cytochalasin post mortem. Experiments post mortem also tested the inference that the positive $d P_{\mathrm{j}} / d t$ after cytochalasin treatment is caused by microvascular filtration. Small volumes (100-200 $\mu \mathrm{l})$ of 50$100 \mu \mathrm{M}$ cytochalasin D ( $n=5$ joints) or $1 \mathrm{mM}$ cytochalasin $\mathrm{D}$ ( $n=4$ joints) or Ringer solution ( $n=6$ joints) were injected into the joint cavity through the pressure 


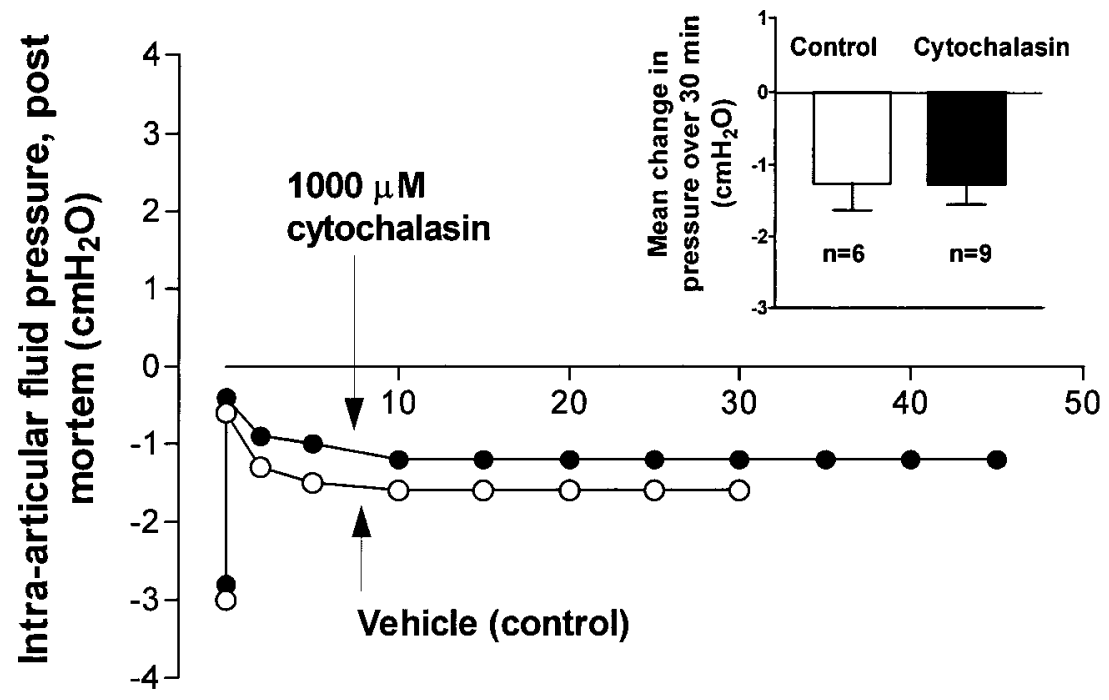

Time (minutes)

FIG. 4. Time course of intra-articular pressure in two knee joints post mortem, following an intra-articular injection of $120 \mu \mathrm{l}$ of $1000 \mu \mathrm{M}$ cytochalasin D solution or vehicle at time zero. The initial injection raised the endogenous, subatmospheric pressure almost to atmospheric pressure. The injectate volume was small in order to facilitate the detection of any progressive negative effect of cytochalasin on pressure. The experiment was carried out post mortem to eliminate microvascular filtration (cf. response in vivo, Fig. 1). (Inset) Mean fall in pressure from postinjection peak over a period of $30 \mathrm{~min}$ in nine joints injected with $50-1000 \mu \mathrm{M}$ cytochalasin D and in six joints injected with vehicle (mean \pm SEM bars; $P=0.97$, unpaired $t$ test).

line after cardiac arrest, and changes in $P_{\mathrm{j}}$ were followed for 30-60 $\mathrm{min}$.

Figure 4 shows that, in marked contrast to the results in vivo, the effects of $1 \mathrm{mM}$ cytochalasin $\mathrm{D}$ and control solution were not significantly different after circulatory arrest. After injection of the drug, $P_{\mathrm{j}}$ decayed slowly. The change in $P_{\mathrm{j}}$ with time closely paralleled that of the control solution, with $P_{\mathrm{j}}$ approaching an asymptote that presumably represented pressure equilibration with the adjacent synovial tissue. Since $d P_{\mathrm{j}} / d t$ after cytochalasin was negative post mortem (Fig. 4) yet positive in vivo (Fig. 1), it is inferred that positive $d P_{\mathrm{j}} / d t$ values in vivo depended on synovial microvascular perfusion.

In contrast to the observations of Berg et al. (2001) in rat skin, there was no evidence for the generation of extra negative pressures by cytochalasin in joints post mortem. The mean fall in $P_{\mathrm{j}}$ over the $30 \mathrm{~min}$ following the injection peak was $-1.26 \pm 0.38 \mathrm{~cm} \mathrm{H}_{2} \mathrm{O}$ for control solution $(n=6)$ and $-1.28 \pm 0.28 \mathrm{~cm} \mathrm{H}_{2} \mathrm{O}$ for cytochalasin D at $50-1000 \mu \mathrm{M}(n=9)$. The difference was not significant $(P=0.97$, unpaired $t$ test). The fall in $P_{\mathrm{j}}$ following injections of cytochalasin D at $1000 \mu \mathrm{M}$ was $-0.71 \pm 0.14 \mathrm{~cm} \mathrm{H}_{2} \mathrm{O}$ over $30 \mathrm{~min}(n=4)$ and $-0.63 \pm 0.24 \mathrm{~cm} \mathrm{H}_{2} \mathrm{O}$ over $45 \mathrm{~min}$. Over a similar period Berg et al. (2001) observed a change of approximately $-2.7 \mathrm{~cm} \mathrm{H}_{2} \mathrm{O}$ in the cytochalasin-injected rat dermis, in contrast to $+0.6 \mathrm{~cm} \mathrm{H}_{2} \mathrm{O}$ in saline-injected controls.

To test whether the volume of the injectate, 100-200 $\mu l$, might have obscured a developing negativity, the experiment was repeated in four more joints using $10-\mu$ injections of $1 \mathrm{mM}$ cytochalasin D delivered from a Hamilton syringe. The results were similar to those in Fig. 4; there was no evidence of the induction of increasingly negative pressures by cytochalasin. Mean pressure was $-2.9 \pm 2.1 \mathrm{~cm} \mathrm{H}_{2} \mathrm{O}$ immediately after the injection and $-2.5 \pm 1.4 \mathrm{~cm} \mathrm{H}_{2} \mathrm{O}$ at $30 \mathrm{~min}$ $(P=0.9, t$ test $)$.

\section{Effect of Cytochalasin D on Interstitial Fluid Pressure; Servonull Micropipette Results}

It could be argued that measurements of $P_{\mathrm{j}}$ failed to detect the putative influence of synoviocytes on interstitial fluid pressure because pressure was recorded in 
a contiguous space rather than in the interstitium itself. Calculations based on the relative compliances of the intra-articular and synovial interstitial compartments indicate that this is unlikely to be the true reason (see Discussion). To address the issue directly, however, we applied the servonull micropipette technique of Berg et al. (2001) to measure the interstitial fluid pressures $\left(P_{\text {if }}\right)$ in the synovium and subsynovium post mortem.

Prior to the interstitial injection of test solution, the synovial and subsynovial interstitial pressures were slightly subatmospheric, with average values of $-0.95 \pm 0.37 \mathrm{~cm} \mathrm{H}_{2} \mathrm{O}(n=18)$ and $-0.81 \pm 0.54 \mathrm{~cm}$ $\mathrm{H}_{2} \mathrm{O}(n=18)$, respectively. Repeated measurements of synovial and subsynovial $P_{\text {if }}$ over $60 \mathrm{~min}$ in two joints that received no interstitial injections showed no significant change with time; none of the four regression slopes of $P_{\text {if }}$ versus time was significantly different from zero $(P \geq 0.3)$, indicating that the tissue hydration was not changing significantly.

The changes in mean $P_{\text {if }}$ over 60 min following the injection of $1.5 \mu \mathrm{l}$ of vehicle or $200-1000 \mu \mathrm{M}$ cytochalasin D are shown in Fig. 5A (synovial $P_{\text {if }}$ ) and 5B (subsynovial $P_{\text {iff }}$ ). Inspection indicated that neither synovial nor subsynovial $P_{\text {if }}$ became consistently more subatmospheric in response to cytochalasin D. Analysis of the results for 0,200 , and $500 \mu \mathrm{M}$ cytochalasin D showed no significant relation between $P_{\text {if }}$ and time ( $P=0.8$, two-way ANOVA). Similarly, the regression slopes fitted to the mean synovial $P_{\text {if }}$ versus time relation over $60 \mathrm{~min}$ for $200 \mu \mathrm{M}\left(0.02 \pm 0.01 \mathrm{~cm} \mathrm{H}_{2} \mathrm{O}\right.$ $\min ^{-1}, n=5$ joints $)$ and $500 \mu \mathrm{M}$ cytochalasin D $(-0.04$ $\pm 0.02, n=4$ ) were not significantly different from zero $(P \geq 0.14)$; only after the control injections did the mean $P_{\text {if }}$ drift slightly but significantly in a negative direction (slope $-0.04 \pm 0.01 \mathrm{~cm} \mathrm{H}_{2} \mathrm{O} \mathrm{min}^{-1}, P=$ $0.01, n=5)$. For subsynovium, none of the regression slopes for $P_{\text {if }}$ versus time were significantly different from zero $(P \geq 0.18)$. Similar results were obtained in two joints injected with $1000 \mu \mathrm{M}$ cytochalasin D; there was no significant increase in the negativity of $P_{\text {if }}$ with time $(n=2)$. By contrast, Berg et al. (2001), observed that $1000 \mu \mathrm{M}$ cytochalasin D caused a progressive negative shift in $P_{\text {if }}$ with time in rat skin, by approximately $-2.7 \mathrm{~cm} \mathrm{H}_{2} \mathrm{O}$ over $60 \mathrm{~min}$.
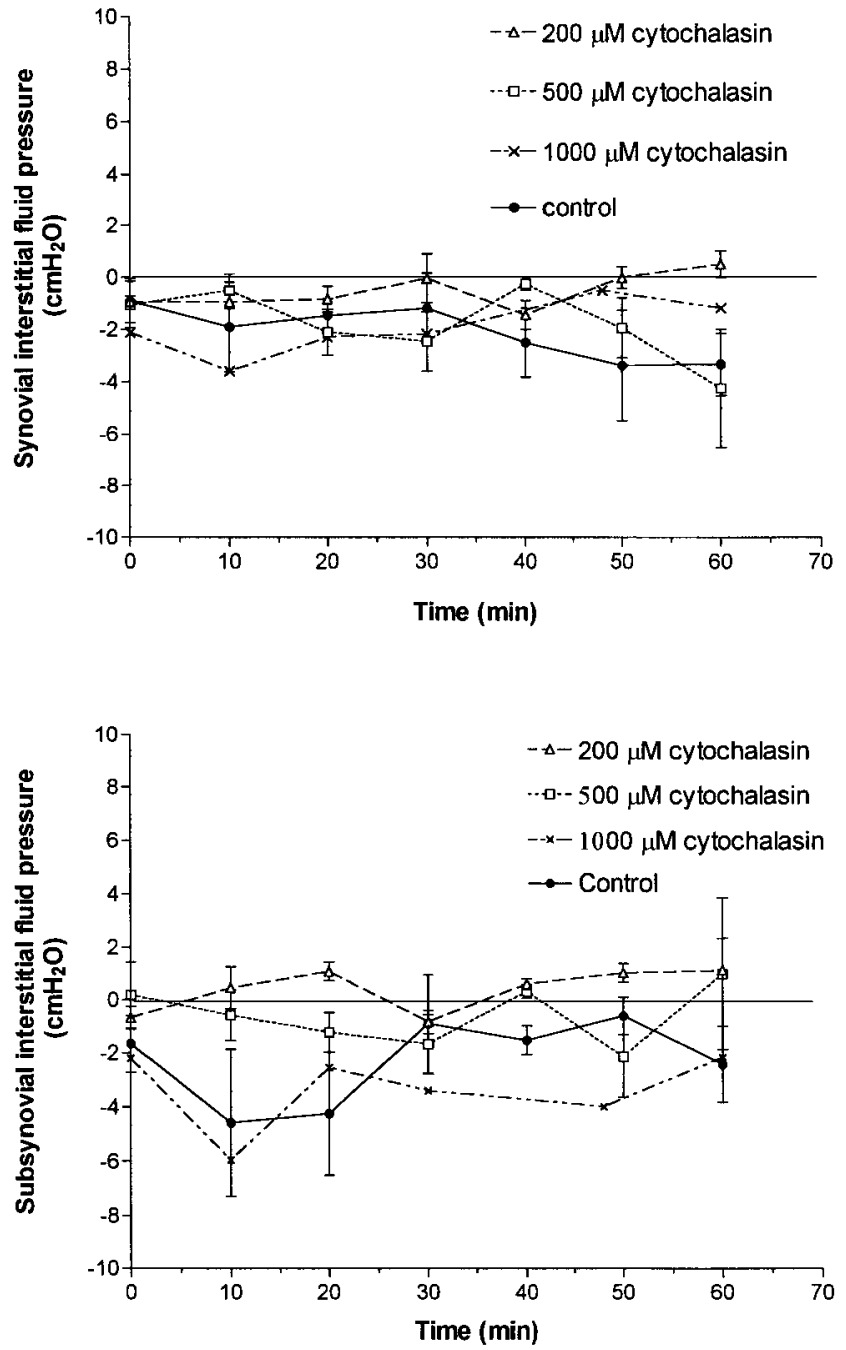

FIG. 5. Effect of cytochalasin D or control solution on interstitial fluid pressure in synovial lining $(\mathrm{A}$; mean $\pm \mathrm{SEM}$ ) or subsynovial connective tissue (B), measured by servonull micropipette post mortem. Interstitial pressure was measured at $\sim 1 \mathrm{~mm}$ from the center of the injection site following the injection of an interstitial bolus of 1.5 $\mu \mathrm{l}$ of control solution $(n=5)$ or $200 \mu \mathrm{M}(n=5), 500 \mu \mathrm{M}(n=4)$, or $1000 \mu \mathrm{M}$ cytochalasin $\mathrm{D}(n=2)$. The measurement plotted at time zero was made immediately prior to the injection.

\section{Half-Lives of Small Solutes in Joint Cavity in Vivo}

Because no method was available to analyze the drug concentrations, intra-articular half-lives were determined for colored solutes of similar molecular size and diffusivity to latrunculin (395 Da) and cytochala$\sin \mathrm{D}(508 \mathrm{Da})$; see Methods. The intra-articular halflives of acridine orange (370 Da), patent blue V (582 
Da), and Evans blue (963 Da) in vivo were respectively $13.8 \pm 2.9 \min (n=5), 24.2 \pm 2.7 \min (n=2)$, and 55.0 $\min (n=1)$. The half-lives correlated significantly with molecular mass (Pearson's $r=0.93, P<0.001$ ). On the basis of these half-lives it is likely that the intra-articular concentration of the drugs fell substantially below the cited nominal concentrations over the 30-min study intervals in vivo.

\section{Half-Lives Post Mortem}

When clearance measurements were made in the contralateral joint post mortem, the intra-articular halflives of acridine orange and patent blue $\mathrm{V}$ increased by $66-107 \%$, to $22.9 \pm 9.5 \mathrm{~min}(n=3)$ and $50.2 \mathrm{~min}$ $(n=1)$, respectively. The difference between the paired results in vivo and post mortem indicated that small solutes are cleared partly into the microcirculation and partly by diffusion into the periarticular tissue $(P=0.08, n=4$, paired $t$ test $)$. Clearance from the cavity was calculated as intra-articular volume $\times$ $0.693 /$ half-life. The difference between the clearance of acridine orange in vivo and post mortem was $55 \pm 5$ $\mu 1 \min ^{-1}$. Since acridine orange is a small, rapidly diffusible molecule that is soluble in both lipid and water (Budavari, 1996), and since fenestrated capillaries have a very high permeability to such solutes, its clearance by synovial capillaries is likely to be partly flow-limited. The above result may thus provide a minimal estimate of synovial microvascular perfusion, namely, $\geq 55 \mu 1 \mathrm{~min}^{-1}$ (see Discussion).

\section{Effect of Cytochalasin on Plasma $\gamma$-globulin Permeation into the Joint Cavity}

If the effect of cytochalasin on filtration is caused by endothelial gap formation, as inferred from studies in vitro (see Introduction), cytochalasin should also increase the permeation of large plasma proteins into the joint cavity. To test this, the net flux of native $\gamma$-globulin into a pair of joint cavities injected with control solution and $100 \mu \mathrm{M}$ cytochalasin D solution, respectively, was analyzed; see Methods. Cytochalasin increased the net $\gamma$-globulin flux into the joint cavity from $0.73 \mathrm{mg} \mathrm{h}^{-1}$ (control) to $1.74 \mathrm{mg} \mathrm{h}^{-1}$. When normalized by the $\gamma$-globulin concentration in plasma from the marginal ear vein, the corresponding clearances of plasma globulin into the joint cavity were 63 $\mu \mathrm{l} \mathrm{h}^{-1}$ (control) and $133 \mu \mathrm{l} \mathrm{h}^{-1}$ (cytochalasin-treated). A more extensive study using labeled bovine albumin showed that intra-articular cytochalasin increases the plasma clearance of albumin into rabbit knee joints (Poli and Levick, 2000).

\section{DISC USSION}

The principle positive findings were that both cytochalasin and latrunculin caused large increases in pressure and fluid filtration into the joint cavity in vivo and that cytochalasin increased the permeation of plasma $\gamma$-globulin into the joint cavity. The $\mathrm{EC}_{50}$ value for these effects was higher than that for cultured endothelia in vitro, but this may be due partly to the short intra-articular half-life of the drug. Even so, near maximal effects were observed at 100-200 $\mu \mathrm{M}$ cytochalasin, which is almost an order of magnitude lower than the concentration of $1 \mathrm{mM}$ used by Berg et al. (2001) to demonstrate statistically significant changes in rat skin.

\section{Endothelial Origin of Increased Permeation of Macromolecules and Fluid}

The increased permeation of $\gamma$-globulin into the joint, and of intravascular labeled albumin (Poli and Levick, 2000), indicates a major increase in microvascular permeability. This may be due to endothelial gap formation, which is a well-documented response in vitro (Shasby et al., 1982; Alexander et al., 1988; Haselton et al., 1989; Holda and Blatter, 1997; Kevil et al., 1998). In support of this, intravascular injections of Monastral blue in vivo demonstrated that intra-articular cytochalasin induces spotty leakage in synovial microvessels (Poli et al., 2001). The high filtration rates could likewise be due to endothelial gap formation; gaps are expected to raise the endothelial conductance and probably reduce the albumin reflection coefficient, which is normally $\geq 0.8$ in synovial capillaries (Knight et al., 1988). A spatially distributed model of trans-synovial flow predicts substantial increases in 
filtration into the joint cavity in response to moderate reductions in effective colloid osmotic pressure across the synovial endothelium (Levick, 1991; Fig. 3C).

The filtration rates induced by cytochalasin may represent a substantial fraction of the synovial plasma flow. Synovial microvascular perfusion is an important parameter for which there is scanty information. The estimate of $\geq 55 \mu \mathrm{l} \mathrm{min}{ }^{-1}$, based on acridine orange clearance in vivo versus post mortem, is of similar magnitude to that inferred from the mean synovial capillary volume (Levick and McDonald, 1989a, b) divided by mean transit time (Funk et al., 1995), namely, $64-128 \mu \mathrm{l} \mathrm{min}^{-1}$ in the rabbit knee; the latter estimate corresponds to a plasma flow of 45-90 $\mu \mathrm{l}$ $\mathrm{min}^{-1}$ for a dynamic microvascular hematocrit of 0.3 . If the synovial plasma flow is, then, of the order $55 \mu \mathrm{l}$ $\mathrm{min}^{-1}$, the filtration rates into the joint cavity of 6.6$12.5 \mu \mathrm{l} \mathrm{min}{ }^{-1}$ in response to $200 \mu \mathrm{M}$ cytochalasin D represent filtration fractions of $12-23 \%$. Although the filtration fraction would be reduced if cytochalasin D raised the synovial blood flow, a pilot study using $\mathrm{N}_{2} \mathrm{O}$ wash-in/washout and an intra-articular $\mathrm{N}_{2} \mathrm{O}$ sensitive electrode provided no evidence of a hyperemic response to cytochalasin.

Since the primary action of cytochalasin and latrunculin is to disrupt actin microfilaments, the results indicate that F-actin is an important structural element in the fenestrated endothelial barrier in vivo. This may be related to the fact that the junctional proteins, such as the cadherin-catenin complex, are restrained spatially in the fluid lipid bilayer by linkages through $\alpha$-actinin to the actin cytoskeleton (Dejana et al., 1995). The results do not exclude the formation of transcellular as opposed to intercellular gaps (Michel and Curry, 1999). Cytoskeleton disassembly can have additional, less direct effects (Janmey, 1999). For example, F-actin disassembly in endothelium but not fibroblasts impairs capacitative $\mathrm{Ca}^{2+}$ entry and impairs receptor-mediated $\mathrm{Ca}^{2+}$ entry in both cell types (Holda and Blatter, 1997; Ribeiro et al., 1997).

\section{Rapidity and Reversibility of D rug Action}

The turnover of F-actin is rapid in many cultured cell lines (Symons and Mitchison, 1991), and cytochalasin in vitro increases the permeability of an arterial endothelial monolayer to dextran by fourfold in 30 min (Kevil et al., 1998). The impressively rapid effects of cytochalasin observed in the present experiments in vivo (Fig. 1) may be due to a very fast turnover of F-actin in the fenestrated endothelium. Studies in vitro show too that the cytochalasin-induced hyperpermeability of monolayers can be reversed within an hour (Shasby et al., 1982; Haselton et al., 1989). The present experiments, which had a time resolution of minutes, showed that reversal begins within minutes of drug washout in vivo (Fig. 3). This may again be the result of a rapid turnover and rebuilding of filamentous actin in synovial endothelium.

\section{D oes Cytochalasin Treatment Affect the Synovial Interstitial Matrix Too?}

Transport between the circulation and joint cavity involves two barriers in series, the endothelium and synovial intercellular matrix, but several lines of evidence point to the endothelium rather than the interstitial layer as the primary responder, as follows. (i) The effect of cytochalasin on $P_{\mathrm{j}}$ was prevented by circulatory arrest (Fig. 1 and 4). (ii) Endothelium is the chief site of resistance to plasma protein permeation, and the reflection of plasma protein by the interstitial layer is negligible (Scott et al., 2000a). (iii) Studies using Monastral blue show the development of endothelial leaks (Poli et al., 2001). (iv) Cytochalasin increases the permeability of endothelial monolayers to albumin (Shasby et al., 1982; Biffl et al., 1995; Lee et al., 1998).

Nevertheless, the findings of Berg et al. (2001) in rat skin introduced the possibility that cytochalasin treatment might also affect the interstitial matrix. If the synoviocyte actin cytoskeleton "braces" the matrix through integrin-collagen linkages, as postulated in rat skin, then cytochalasin treatment could in principle induce a more negative interstitial fluid pressure. The servonull micropipette measurements of interstitial pressures post mortem showed, however, that cytochalasin had no more effect on synovial or subsynovial interstitial fluid pressure than did control solution. Nothing resembling the extra $-2.7 \mathrm{~cm} \mathrm{H}_{2} \mathrm{O}$ interstitial pressure observed in rat skin post mortem (Berg et al., 2001) was detected in the present study. Likewise the 
effect of cytochalasin or latrunculin on intra-articular pressure post mortem was no different from that of vehicle (Fig. 4), even when the injectate volume was only $10 \mu$ l. The reasoning behind the intra-articular study was that any increase in the swelling tendency of synovial interstitium will cause the absorption of some intra-articular fluid post mortem and thus reveal itself by a fall in intra-articular pressure. The extent to which intra-articular pressure can be expected to mirror changes in periarticular swelling pressure depends on the relative volume and compliance of the synovial cavity and the periarticular tissue. Calculations using estimates of compartment volumes and compliance from Knight and Levick, (1982), Levick and McDonald (1989a, b), Price et al. (1996), and Scott et al. (2000b) indicate that if the synovium and subsynovium developed an extra $-2.7 \mathrm{~cm} \mathrm{H}_{2} \mathrm{O}$ swelling pressure, the intra-articular pressure would change by $-1.6 \mathrm{~cm}$ $\mathrm{H}_{2} \mathrm{O}$, given an injection volume of $10 \mu \mathrm{l}$ at subatmospheric joint pressure (the optimal conditions for detecting the putative effect). Despite its inferred detectability, no such response was seen. The results, therefore, provided no support for the hypothesis that in rabbit synovium the actin cytoskeleton of the fibroblasts (synoviocytes) directly influences the matrix fluid pressure.

To summarize, the study showed that endothelial F-actin has a major role in determining the normal synovial microvascular resistance to fluid filtration and plasma $\gamma$-globulin permeation. F-actin disruption is thus a potential factor in the link between proinflammatory mediators and the formation of arthritic joint effusions. The results provided no support for the hypothesis that synoviocyte F-actin also influences the swelling tendency of synovial matrix and hence its hydration and permeability.

\section{ACKNOWLEDGMENTS}

We gratefully acknowledge stimulating discussion of the effects of cytochalasin with Professor R. Reed and Dr. H. Wiig of Bergen University, Norway. The research was funded by European Union TMR Grant ERBFMRXCT980219 and The Wellcome Trust Grant $056983 / \mathrm{Z} / 99$.

\section{REFERENCES}

Alberts, B., Bray, D., Lewis, J., Raff, M., Roberts, K., and Watson, J. D. (1994). "Molecular Biology of the Cell," 3rd ed. Garland, New York.

Alexander, J. S., Hechtman, H. B., and Shepro, D. (1988). Phalloidin enhances barrier function and reduces inflammatory permeability in vitro. Microvasc. Res. 35, 308-315.

Asari, A., Kuriyama, S., Kuminami, E., and Uchiyama, Y. (1995). Cytochemical localization of hyaluronic acid in human synovium with special reference to its possible process of degradation. Arch. Histol. Cytol. 58, 65-76.

Baldwin, A., and Thurston, G. (1995). Changes in endothelial actin cytoskeleton in venules with time after histamine treatment. Am. J. Physiol. 269, H1528-H1537.

Berg, A., Ekwall, A. H., Rubin, K., Stjernschantz, J., and Reed, R. K. (1998). Effect of $\mathrm{PGE}_{1} \mathrm{PGI}_{2}$ and $\mathrm{PGF}_{2 \alpha}$ analogs on collagen gel compaction in vitro and interstitial pressure in vivo. Am. J. Physiol. 274, H663-H671.

Berg, A., Rubin, K., and Reed, R. K. (2001). Cytochalasin D induces edema formation and lowering of interstitial fluid pressure in rat dermis. Am. J. Physiol. 281, H7-H13.

Biffl, W. L., Moore, E. E., Moore, F. A., Carl, V. S., Francoise, R. J., and Banerjee, A. (1995). Interleukin-8 increases endothelial permeability independent of neutrophils. J. Trauma 39, 98-102.

Budavari, S. (Ed.) (1996). "The Merck Index," 12th ed., Merck, Rahway, NJ,

Coleman, P. J., Scott, D., Mason, R. M., and Levick, J. R. (1999). Characterization of the effect of high molecular weight hyaluronan on trans-synovial flow in rabbit knees. J. Physiol. 514, 265-282.

Cooper, J. A. (1987). Effects of cytochalasin and phalloidin on actin. J. Cell Biol. 105, 1473-1478.

Coué, M., Brenner, S. L., Spector, I., and Korn, E. D. (1987). Inhibition of actin polymerization by latrunculin A. FEBS Lett. 213, 316-318.

Dejana, E., Corada, M., and Lampugnani, M. G. (1995). Endothelial cell-to-cell junctions. FASEB J. 9, 910-918.

de Oliveira, C. A., and Mantovani, B. (1988). Latrunculin is a potent inhibitor of phagocytosis by macrophages. Life Sci. 43, 1825-1830.

Edwards, J. C. W. (1999). The biology of synovial cells. In "Biology of the Synovial Joint" (C. W. Archer, B. Caterson, M. Benjamin, and J. R. Ralphs, Eds.), pp. 225-233. Harwood, Amsterdam.

Ehringer, W. D., Yamany, S., Steier, K., Farag, A., Roisen, F. J., Dozier, A., and Miller, F. N. (1999). Quantitative image analysis of F-actin in endothelial cells. Microcirculation 6, 291-303.

Ermert, L., Bruckner, H., Walmrath, D., Grimminger, F., Aktories, K., Suttorp, N., Duncker, H. R., and Seeger, W. (1995). Role of endothelial cytoskeleton in high-permeability edema due to botulinum C2 toxin in perfused rabbit lungs. Am. J. Physiol. 268, L753-761.

Funk, R. H. W., Tischendorf, R., and Bratengeier, H. (1995). Microendoscopy of the synovial vasculature in the rabbit knee joint. Microvasc. Res. 50, 45-55. 
Haselton, F. R., Mueller, S. N., Howell, R. E., Levine, E. M., and Fishman, A. P. (1989). Chromatographic demonstration of reversible changes in endothelial permeability. J. Appl. Physiol. 67, 2032-2048.

Henderson, K. J., Pitsillides, A. A., Edwards, J. C. W., and Worrall, J. G. (1993). Reduced expression of CD44 in rheumatoid synovial cells. Br. J. Rheumatol. 32(Suppl. 1), 25.

Holda, J. R., and Blatter, L. A. (1997). Capacitative calcium entry is inhibited in vascular endothelial cells by disruption of cytoskeletal microfilaments. FEBS Lett. 403, 191-196.

Janmey, P. A. (1999). The cytoskeleton and cell signaling: Component localisation and mechanical coupling. Physiol. Rev. 78, 763-781.

Kevil, C. G., Okayam, N., Trocha, S. D., Kalogeris, T. J., Coe, L. L., Specian, R. D., Davis, C. P., and Alexander, J. S. (1998). Expression of zonula occudens and adherens junctional proteins in human venous and arterial endothelial cells: Role of occludin in endothelial solute barriers. Microcirculation 5, 197-210.

Knight, A. D., and Levick, J. R. (1982). Pressure-volume relationships above and below atmospheric pressure in the synovial cavity of the rabbit knee. J. Physiol. 328, 403-420.

Knight, A. D., and Levick, J. R. (1983). The density and distribution of capillaries around a synovial cavity. Quart. J. Exp. Physiol. 68, 629-644.

Knight, A. D., Levick, J. R., and McDonald, J. N. (1988). Relation between trans-synovial flow and plasma colloid osmotic pressure, with an estimation of the albumin reflection coefficient in the rabbit knee. Quart. J. Exp. Physiol. 73, 47-65.

Korthuis, R. J., Carden, D. L., Kvietys, P. R., Shepro, D., and Fuseler, J. (1991). Phalloidin attenuates postischemic neutrophil infiltration and increased microvascular permeability. J. Appl. Physiol. 71, 1261-1269.

Lacy, B. E., and Underhill, C. B. (1985). The hyaluronate receptor is associated with actin filaments. J. Cell Biol. 105, 1395-1404.

Lee, H. Z., Lin, W. C., Yeh, F. T., and Wu, C. H. (1998). 2-Phenyl-4quinolone prevents serotonin-induced increases in endothelial permeability to albumin. Eur. J. Pharmacol. 354, 205-213.

Levick, J. R. (1991). A two-dimensional morphometry-based model of interstitial and transcapillary flow in rabbit synovium. Exp. Physiol. 76, 905-201.

Levick, J. R., and McDonald, J. N. (1989a). Synovial capillary distribution in relation to altered pressure and permeability in knees of anaesthetized rabbits. J. Physiol. 419, 477-492.

Levick, J. R., and McDonald, J. N. (1989b). Ultrastructure of transport pathways in stressed synovium of the knee in anaesthetized rabbits. J. Physiol. 419, 493-508.

Levick, J. R., Price, F. M., and Mason, R. M. (1996). Synovial matrixsynovial fluid system of joints. In "Extracellular Matrix, Vol. I, Tissue Function" (W. D. Comper, Ed.), pp. 328-377. Harwood, Amsterdam.

Michel, C. C., and Curry, F. E. (1999). Microvascular permeability. Physiol. Rev. 79, 703-761.

Miserocchi, G., Negrini, D., and Gonano, C. (1990). Direct measurement of interstitial pulmonary pressure in in situ lung with intact pleural space. J. Appl. Physiol. 69, 2168-2174.
Poli, A., Coleman, P. J., Mason, R. M., and Levick, J. R. (2001). Role of F-actin in synovial permeability. J. Vasc. Res. 38, 402.

Poli, A., and Levick, J. R. (2000). Effect of actin filament disrupter, cytochalasin D (CyD), on fluid and solute exchange in synovial joints. J. Vasc. Res. 37(Suppl 1), A65, p27.

Price, F. M., Levick, J. R., and Mason, R. M. (1996). Changes in glycosaminoglycan concentration and synovial permeability at raised intra-articular pressures in rabbit knees. J. Physiol. 495, 821-833.

Reed, R. K., Woie, K., and Rubin, K. (1997). Integrins and control of interstitial pressure. News Physiol. Sci. 12, 42-48.

Ribeiro, C. M. P., Reece, J., and Putney, J. W. (1997). Role of the cytoskeleton in calcium signalling in NIH $3 \mathrm{~T} 3$ cells. An intact cytoskeleton is required for agonist-induced $\left[\mathrm{Ca}^{2+}\right]$ signaling, but not for capacitative calcium entry. J. Biol. Chem. 272, 26555-26561.

Rinaldi, N., SchwarzEywill, M., Weiss, D., LeppepmannJansen, P., Lukoschek, M., Keilholz, U., and Barth, T. F. E. (1997). Increased expression of integrins on fibroblast-like synoviocytes from rheumatoid arthritis in vitro correlates with enhanced binding to extracellular matrix proteins. Ann. Rheumatic Dis. 56, 45-51.

Scott, D., Coleman, P. J., Mason, R. M., and Levick, J. R. (2000a). Interaction of intra-articular hyaluronan and albumin in the attenuation of fluid drainage from joints. Arthritis Rheum. 43, 1175-1182.

Scott, D., Poli, A., Bertin, K., Levick, J. R., and Miserocchi, G. (2000b). Evidence that thin interstitial layer around joints acts as a high resistance 'skin' to retain joint fluid. J. Vasc. Res. 37(Suppl. 1), A68, 28.

Shasby, D. M., Shasby, S. S., Sullivan, J. M., and Peach, M. J. (1982). Role of endothelial cell cytoskeleton in control of endothelial permeability. Circ. Res. 51, 657-661.

Spector, I., Shocket, N. R., Kashman, Y., and Groweiss, A. (1983). Latrunculins: Novel marine toxins that disrupt microfilament organization in cultured cells. Science 219, 493-495.

Symons, M. H., and Mitchison, T. J. (1991). Control of actin polymerization in live and permeabilised fibroblasts. J. Cell Biol. 114, 503-513.

Takenaga, K., Olden, K., and Yamada, K. M. (1990). Analysis of the interaction between the fibronectin receptor and cytoskeletal proteins in human fibroblasts. A chemical crosslinking study. J. Cell Biol. 111, 299a.

Unemori, E. N., and Werb, Z. (1986). Reorganization of polymerized actin: A possible trigger for induction of procollagenase in fibroblasts cultured in and on collagen gels. J. Cell Biol. 103, 1021-1031.

Wallis, W. J., Simkin, P. A., and Nelp, W. B. (1987). Protein traffic in human synovial effusions. Arthritis Rheum. 30, 57-63.

Wang, N. (1998). Mechanical interactions among cytoskeletal filaments. Hypertension 32, 162-165.

Ward, A. C., Dowthwaite, G. P., and Pitsillides, A. A. (1999). Hyaluronan in joint cavitation. Biochem. Soc. Trans. 27, 128-135.

Wiig, H., Reed, R. K., and Aukland, K. (1981). Micropuncture measurements of interstitial fluid pressure in rat subcutis and skeletal muscle: Comparison to wick-in-needle technique. Microvasular Res. 21, 308-319. 